\title{
Retrospective study of 70 cases of severe frostbite lesions: a proposed new classification scheme
}

\author{
EMMANUEL CAUCHY, MD; ERIC CHETAILLE, MD; VINCENT MARCHAND, MD; \\ BERNARD MARSIGNY, MD
}

From the Department of Mountain Medicine and Trauma, Chamonix Hospital, Chamonix, France.

\begin{abstract}
Objective.-Previous frostbite classifications were mainly based on retrospective diagnosis and, most of the time, could not be used to predict the final outcome of the lesions and especially the probability of an amputation and its level. The aim of this study was to suggest a new classification at day 0 based mainly on the topography of the lesions and on early bone scan results, which are more convenient and accurate in predicting the final outcome of frostbites.
\end{abstract}

Methods.- The retrospective study of the clinical histories of 70 patients hospitalized at Chamonix Hospital (Mont-Blanc Massif) from 1985 to 1999 for severe frostbite injuries of the extremities has allowed us to classify the aspects of the initial lesions on day 0 and to compare them with final outcomes.

Results. - A strong correlation was found between the extent of the lesion and the outcome of each finger or toe. When the initial lesion was on the distal phalanx, the probability of bone amputation was around $1 \%$ for the digit, $31 \%$ for the middle phalanx, $67 \%$ for the proximal phalanx, $98 \%$ for the metacarpal $/$ metatarsal, and $100 \%$ for the carpal $/$ tarsal.

Conclusions. - Based on these clinical results and on the results of bone scans (previously validated), a new classification of frostbite severity at day 0 is proposed. Four degrees of severity are defined: first degree, leading to recovery; second degree, leading to soft tissue amputation; third degree, leading to bone amputation, and fourth degree, leading to large amputation with systemic effects.

Key words: frostbite, bone scan, topography, classification, prognosis

\section{Introduction}

Cold-induced lesions are very often the result of an inability to protect oneself from an adverse environment. A localized cold-induced lesion, or frostbite, is defined as tissue injury resulting from prolonged exposure of flesh to a temperature less than $0^{\circ} \mathrm{C}$. These injuries frequently afflict people active in polar environments such as skiers and mountaineers. Frostbite injury most often involves the hands and feet and less often the ears, nose, and cheeks. The seriousness of the lesion essentially depends on the severity, the duration of exposure to the cold, and the means used to protect oneself.

Every year, the Chamonix Hospital treats a large number of patients, most of whom are mountaineers or skiers, suffering from frostbite injuries of the extremities.

Corresponding author: Emmanuel Cauchy, MD, Department of Mountain Medicine and Trauma, Hôpital de Chamonix, 509 Route des Pélerins, BP30 Les Bossons, 74400 Chamonix, France (e-mail: M.Cauchy@CH-SALLANCHES-CHAMONIX.fr).
Those with serious lesions are hospitalized to facilitate treatment and healing. Frostbites requiring tissue or bone amputation are usually identified retrospectively after a few weeks of hospitalization.

Early establishment of the prognosis for patients with frostbite is hampered by the lack of useful, early, clinical guidelines. ${ }^{1}$ The 3 - to 6 -week waiting period often necessary to determine the severity of the lesion and the prospect of amputation often causes mental anguish for patients. In addition, most recent hypotheses regarding frostbite pathology evoke the possibility of a secondary, progressive phase of necrosis in the first 48 hours following the primary phase, where vasospasm of frozen tissue predominates. ${ }^{2}$ Current research efforts are focused on this secondary phase, where the use of experimental vasoactive drugs and potent antioxidants such as prostacyclin ${ }^{3}$ and fibrinolytics (recombinant tissue plasminogen activator [r-TPA] $)^{4,5}$ are administered in the first 48 hours. To effectively compare treatment regimes, 
one should start with an accurate initial assessment of the extent of the frostbite. Many authors suggest a classification based on the frostbite aspects observed at different stages of evolution, considering the depth of the lesion as for a burn injury without considering the extent of topography. ${ }^{6-10}$ The only topographic classification for cold injury was proposed by Killian, ${ }^{11}$ but the relationship with the final outcome was not studied.

The large number of frostbite injuries treated at our institution allowed us to precisely describe initial lesion characteristics just after rewarming. The relationship between the extent of the initial lesion immediately and following rewarming was assessed, and the final outcome was studied with the aim of developing a classification scheme for the early evaluation of frostbite severity.

\section{Materials and methods}

\section{SUBJECTS}

An average of 80 patients with frostbite injuries to the hands and feet present to the Chamonix Hospital every year. Between 1973 and 2000, 719 were hospitalized for deep second- or third-degree frostbite according to the classification proposed by Foray and Allamel ${ }^{12}$ and were considered to have severe frostbite injuries for the purposes of this study. The need for hospitalization was decided by the extent and features of frostbite lesions, including the hypoanesthesic area, and cyanosis involving at least 1 finger or toe phalanx after external rewarming (1 hour in a $38^{\circ} \mathrm{C}$ bath). Among hospitalized patients, 70 were selected retrospectively for the study. The time between natural rewarming and evaluation had to be no more than 48 hours. Their initial records must have contained a complete clinical description of the lesion on day 0 with sketches and/or photos, and followup must have been complete.

\section{TREATMENT PROTOCOL}

All patients received rapid rewarming in a $38^{\circ} \mathrm{C}$ bath with aspirin (250-mg IV) and chlorohydrate of buflomedil (400-mg IV). ${ }^{13}$ Beyond this, the choice of treatment was variable and may have included one or more of the following approaches: hemodilution, platelet aggregation inhibitor (aspirin), peripheral vasodilators (ketanserin ${ }^{14}$ or chlorohydrate of buflomedil ${ }^{15}$ ), prostacyclin analogs (iloprost), ${ }^{3}$ and fibrinolytics (streptokinase, urokinase, or r-TPA ${ }^{4,5}$ ).

The different treatments were classified into 11 groups to assess correlation with the final outcome: 1) aspirin, 2) chlorohydrate of buflomedil, 3) iloprost, 4) r-TPA, 5) heparin, 6) dextran, 7) nonsteroidal anti-inflammatory agents, 8) naftidrofuryl, 9) hemodilution, 10) ketanserin, and 11) low-molecular-weight heparin. During the treatment, all patients had an initial bone scan near day 2 . The scintigraphic method used was technetium $99 \mathrm{~m}$ pertechnetate.

\section{GRADING OF EXTENT}

Two independent investigators reinterpreted the patients' medical histories, including the extent of the initial lesions and the final amputation results. To create a baseline for our group of patients on day 0 , we determined the initial lesion extent after rapid rewarming. Two kinds of frostbite injuries were identified on admission: frostbite due to 1) conductive cooling (eg, associated with compression from shoes or use of the hands to build a snow cave), which was usually overvaluated compared to the frostbite due to 2) convective cooling. ${ }^{16}$

The initial lesions on each digit were quantified using a scale of 0 to 5: $0=$ no lesion, $1=$ lesion on the distal phalanx, $2=$ lesion on the middle phalanx or proximal phalanx for the thumb/big toe, $3=$ lesion on the proximal phalanx except for the thumb/big toe, $4=$ lesion on the metacarpal/metatarsal, and $5=$ lesion on the carpal/tarsal. In terms of final outcome, lesions on each digit were graded according to need for bone amputation $(0=$ no amputation and $1=$ amputation regardless of the level).

\section{STATISTICAL ANALYSIS}

The evolution of each lesion was studied independently to evaluate any correlation between the initial clinical aspects of the lesion (defined by a grayness or cyanotic hypoanesthesic area) and its outcome, which was recorded usually more than 1 month later ( \pm necrosis; \pm bone amputation). The presence of an initial lesion on a phalanx that subsequently required an amputation was rated as a true positive. The presence of an initial lesion without subsequent need for amputation was a false positive. The absence of an initial lesion and no amputation was a true negative. The absence of an initial lesion in a digit ultimately requiring amputation was a false negative. Positive predictive values were calculated based on the final outcomes of lesions. The probability of bone amputation was determined (positive predictive value) with a $95 \%$ CI. A chi-square test was used to compare the frequencies of final outcomes of bone amputations.

\section{Results}

\section{PATIENTS}

After examining 719 patients, only 70 met all inclusion criteria ( 7 women, 63 men; mean age $=31.9$ years). 
Thirty patients $(42.5 \%)$ sustained frostbite injuries involving the hands, and $28(40 \%)$ had frostbite injuries involving the feet, with $12(17.5 \%)$ patients having injuries to both hands and feet. Five patients had a past medical history of prior superficial frostbite injury. Thirteen patients $(20.5 \%)$ had associated problems: hypothermia in 9 patients $(12.3 \%)$ and 6 with various traumatic injuries $(8.2 \%)$. Sixty-eight of 70 patients sustained their cold exposure while mountain climbing in the Mont-Blanc Massif. In the remaining 2, frostbite was related to alcohol intake or a psychiatric disorder leading to prolonged exposure to a cold environment. None had a history of peripheral vascular disease or diabetes, but 3 were smokers. For most patients, frostbites were the result of an unanticipated exposure to cold with inadequate protection due to poor knowledge of the terrain, dehydration, and/or exhaustion.

\section{THE INITIAL LESION}

The initial lesion at hospitalization was characterized by cyanosis and grayness in color, which extended from the digit tip in a centripetal, ascending character toward the base of the limb. This aspect persisted despite rapid rewarming and was accompanied by anesthesia. In the study group, there were no blisters within 12 hours of beginning rewarming, except in 1 case with associated skin trauma (related to use of the hands to build a snow cave). For a few cases, the lesion was more heterogeneous with associated edema. The limit of the initial lesion was usually quite well demarcated just after initial treatment.

\section{ANALYSIS OF EXTENT}

Each hand/foot that developed at least 1 severe lesion on a digit was analyzed with the other unaffected digits of the same hand/foot. Three hundred sixty-five fingers were monitored, with 239 being affected. Of 350 toes monitored, 255 were affected.

The results are presented in Table 1. For both the hands and feet, when lesions were localized to the distal phalanx, the probability of amputation approached 0 . The probability of amputation increased progressively as more of the digit was involved, reaching $100 \%$ when the entire finger or toe was initially involved. The specificity of the appearance of the initial lesion compared to the final outcome was very low, around $30 \%$ (data not shown), indicating that the final amputation level has a low correlation with the initial clinical aspect of the lesion.

The risk of amputation was greater for the hands compared to the feet but not significantly.
Table 1. Probability of amputation based on the extent of the initial lesion

\begin{tabular}{llc}
\hline \multicolumn{1}{c}{$\begin{array}{c}\text { Extent } \\
\text { (level of } \\
\text { involvement) }\end{array}$} & $\begin{array}{c}\text { Probability } \\
\text { of bone } \\
\text { amputation } \\
(95 \% \text { CI) }\end{array}$ \\
\hline Hand & 5 (carpal/tarsal) & 100 \\
& 4 (metacarpal/metatarsal) & 100 \\
3 (proximal phalanx) & $83(66 ; 100)$ \\
Foot & (intermediary phalanx) & $39(25 ; 52)$ \\
& 1 (distal phalanx) & $1(00 ; 03)$ \\
& 5 (carpal/tarsal) & 100 \\
& 4 (metacarpal/metatarsal) & $98(93 ; 100)$ \\
3 (proximal phalanx) & $60(45 ; 74)$ \\
& 2 (intermediary phalanx) & $23(10 ; 35)$ \\
1 Hand and foot & 0 \\
& 5 (cartal phalanx) & 100 \\
& 4 (metacarpal/metatarsal) & $98(95,100)$ \\
& 3 (proximal phalanx) & $67(55 ; 79)$ \\
2 (intermediary phalanx) & $31(22 ; 41)$ \\
1 (distal phalanx) & $1(00 ; 02)$ \\
\hline
\end{tabular}

No correlation by treatment protocol was found between the extent of the initial lesion and the final outcome, even after pooling the treatment drug by categories (data not shown). This was likely due to the small patient numbers in each group, the lack of standardized treatment protocols, and the retrospective, noncontrolled study design.

\section{Discussion}

This retrospective study of patients with severe frostbite of the extremities demonstrates the importance of the extent of the initial lesion in predicting need for amputation. The relation between the initial frostbite topography and the final outcome was evaluated and quantified for the first time. The results suggest that the severity of the final outcome is correlated with the extent of the initial lesions. The extent of the initial lesion could not, however, be used to predict the level of the amputation. For this reason, isotopic bone scans (2-phase bone scanning [99mTc-HMDP]) should be done to complete the evaluation. Cauchy et al. ${ }^{17}$ previously evaluated and published the prognostic value of 2-phase $99 \mathrm{mTc}$ bone scanning performed on 92 patients who presented with severe frostbite of the extremities. The study showed that an initial bone scan, as early as on the third day, has excellent specificity in evaluating the severity of frostbite injury. There was a direct correlation between the 
Table 2. Proposed classification scheme for severity of frostbite injuries

\begin{tabular}{|c|c|c|c|c|}
\hline $\begin{array}{l}\text { Frostbite injuries } \\
\text { of the extremities }\end{array}$ & $\begin{array}{l}\text { Grade 1 } \\
\text { (Figure 1) }\end{array}$ & $\begin{array}{c}\text { Grade 2 } \\
\text { (Figure 2) }\end{array}$ & $\begin{array}{l}\text { Grade } 3 \\
\text { (Figure 3) }\end{array}$ & $\begin{array}{l}\text { Grade } 4 \\
\text { (figure 4) }\end{array}$ \\
\hline $\begin{array}{l}\text { Extent of initial lesion } \\
\text { at day } 0 \text { after rapid } \\
\text { rewarming }\end{array}$ & $\begin{array}{l}\text { Absence of initial } \\
\text { lesion }\end{array}$ & $\begin{array}{l}\text { Initial lesion on distal } \\
\text { phalanx }\end{array}$ & $\begin{array}{l}\text { Initial lesion on } \\
\text { intermediary (and) } \\
\text { proximal phalanx }\end{array}$ & $\begin{array}{l}\text { Initial lesion on carpal/ } \\
\text { tarsal }\end{array}$ \\
\hline $\begin{array}{l}\text { Bone scanning at } \\
\text { day } 2\end{array}$ & Useless & $\begin{array}{l}\text { Hypofixation of } \\
\text { radiotracer uptake } \\
\text { area }\end{array}$ & $\begin{array}{l}\text { Absence of radiotracer } \\
\text { uptake area on the digit }\end{array}$ & $\begin{array}{l}\text { Absence of radiotracer } \\
\text { uptake area on the } \\
\text { carpal/tarsal }\end{array}$ \\
\hline Blisters at day 2 & Absence of blisters & Clear blisters & $\begin{array}{l}\text { Hemorrhagic blisters on } \\
\text { the digit }\end{array}$ & $\begin{array}{l}\text { Hemorrhagic blisters over } \\
\text { carpal/tarsal }\end{array}$ \\
\hline \multirow[t]{2}{*}{ Prognosis at day 2} & No amputation & Tissue amputation & Bone amputation of digit & $\begin{array}{l}\text { Bone amputation of the } \\
\quad \text { limb } \\
\pm \text { systemic involvement } \\
\pm \text { sepsis }\end{array}$ \\
\hline & No sequelae & Fingernail sequelae & Functional sequelae & Functional sequelae \\
\hline
\end{tabular}

uptake limit in the phalanges and the eventual level of amputation. The probability of an amputation was around $84 \%$ in the case of scan images demonstrating lack of radioactive tracer uptake. A second scan, on approximately day 8 , was even more sensitive and informative, especially for initial scintigraphic hypofixated lesions. A strong correlation was shown between a positive uptake of the radiotracer and the probability of healing (around 99\%).

Taking into account our results, a new classification is proposed. This new classification (Table 2) can be used immediately after rewarming of the frostbitten extremity to determine prognosis of the frozen lesions. Four severity levels are proposed, and the main differences from the previous classification scheme include the following:

1. Earlier prediction of the final outcome of the frostbite is possible (a minimum of 15 days was required with previous classifications);

2. At day 2, the approximate level for amputation is known; and

3. The new scale can be used to precisely classify the frozen lesions and manage the patient, even without any specific knowledge of the topic on the part of the treating physician.

Taking into account the low risk of amputation, Grade 1 (Figure 1) and 2 (Figure 2) lesions do not need hospitalization or bone scanning. Treatment with rapid rewarming over 60 minutes in a $38^{\circ} \mathrm{C}$ bath with antiseptic, aspirin, vasodilators by oral route for 8 to 21 days, and local treatment would be sufficient in most of these cases.

Grade 3 (Figure 3) injuries are correlated with an important risk of amputation, and patients should be hos- pitalized immediately for the same medical treatment (aspirin and chlorohydrate of buflomedil) but by an intravenous route. An isotopic bone scan performed on day 2 will allow a more precise determination of the extent of the frozen lesions and delimitation of the level of bone amputation. In the case of an abnormal result, surgical intervention should be planned after a second bone scan on day 8 (to allow stabilization of the frostbite bone lesions).

Grade 4 (Figure 4) lesions have a high probability of amputation and a high risk of major complications (eg, thrombosis, sepsis, and systemic involvement), which may require hospitalization in an intensive care unit. The use of more aggressive treatments such as thrombolytics or prostacycline might be appropriate. Even following prophylactic antibiotics, early amputation is often needed due to major sepsis. In such cases, the amputation level could be determined by the results of the isotopic bone scan. This alternative is particularly appropriate for those cases of severe frostbite in patients who are malnourished, weak, or have hepatocellular dysfunction. The operative approach may vary by surgeon's preference (amputation in 1 or 2 steps or salvage with flap transfer, etc). Early amputation decreases overall hospitalization and hastens reconstructive surgery. ${ }^{18}$ The proposed management algorithm is listed in Table 3 .

This proposed classification scheme may be useful in clinical trials evaluating various frostbite therapies. Prospective controlled studies are needed to validate the clinical efficacy of proposed therapies. This classification scheme may be modified in the future as new diagnostic modalities such as laser Doppler or magnetic nuclear resonance imaging are studied in the setting of 


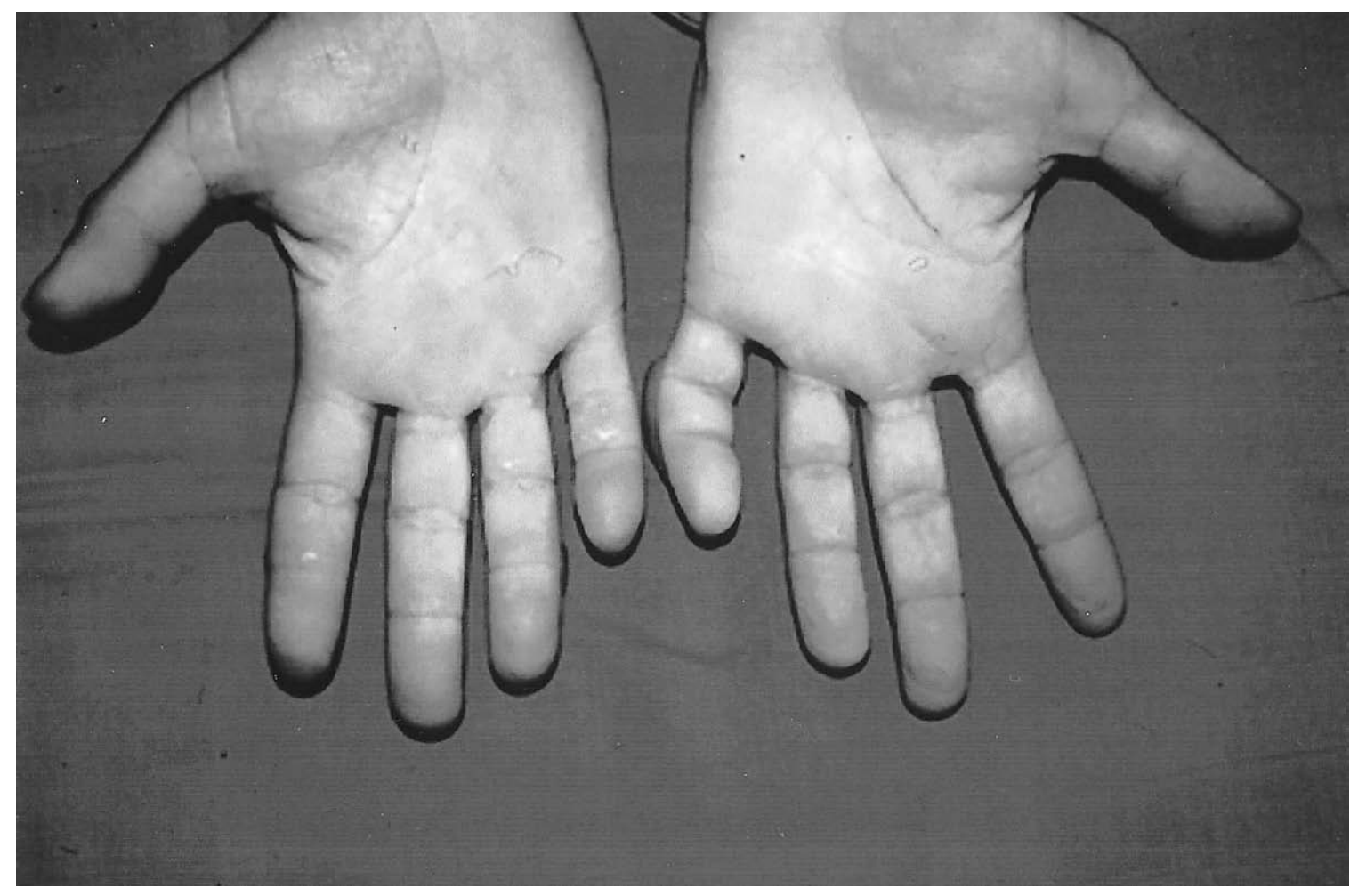

Figure 1. Frostbite injury of the hand at day 0: no initial lesion except erythema (Grade 1).

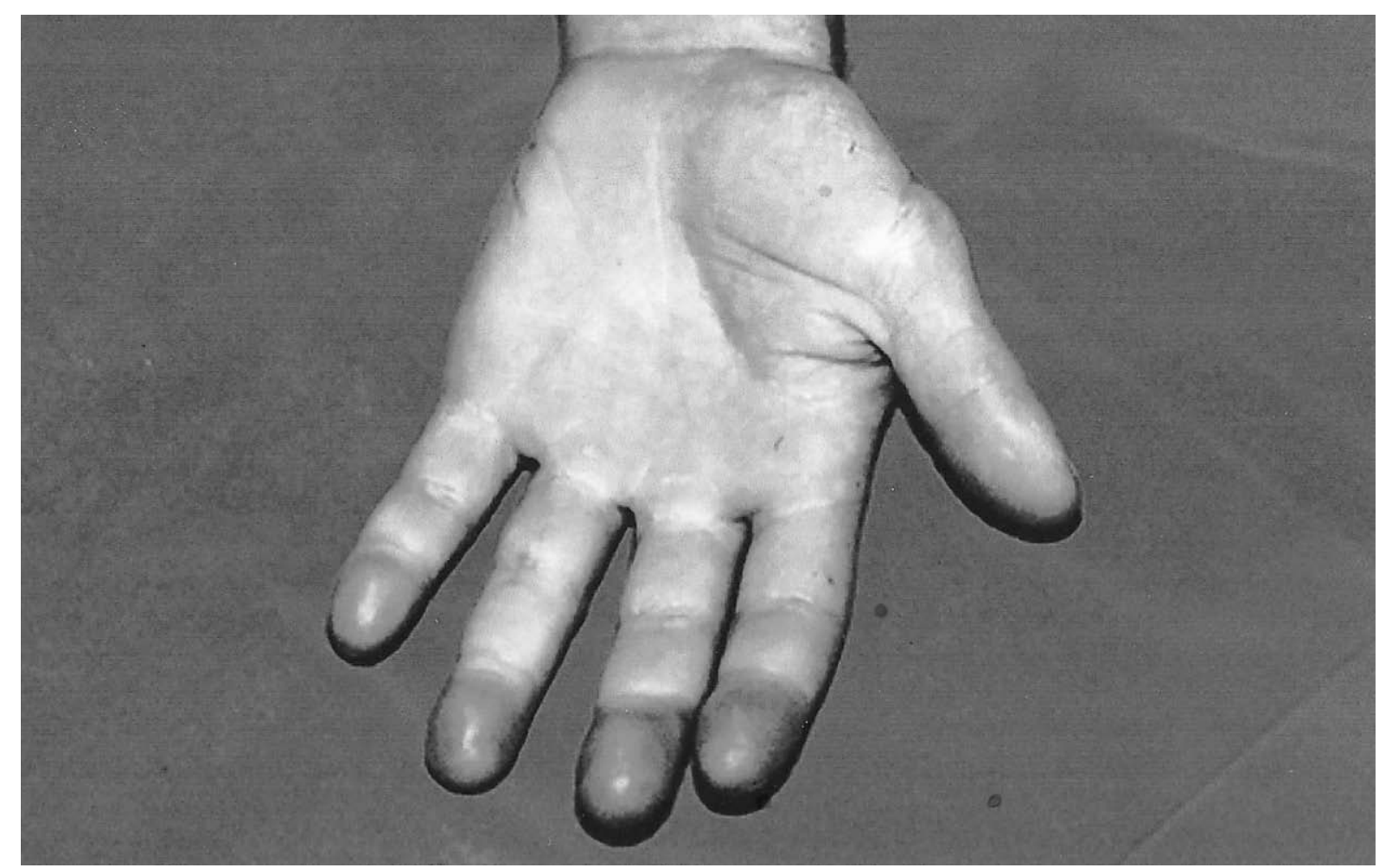

Figure 2. Frostbite injury of the hand at day 0: initial lesion limited to the distal phalanx (Grade 2). 


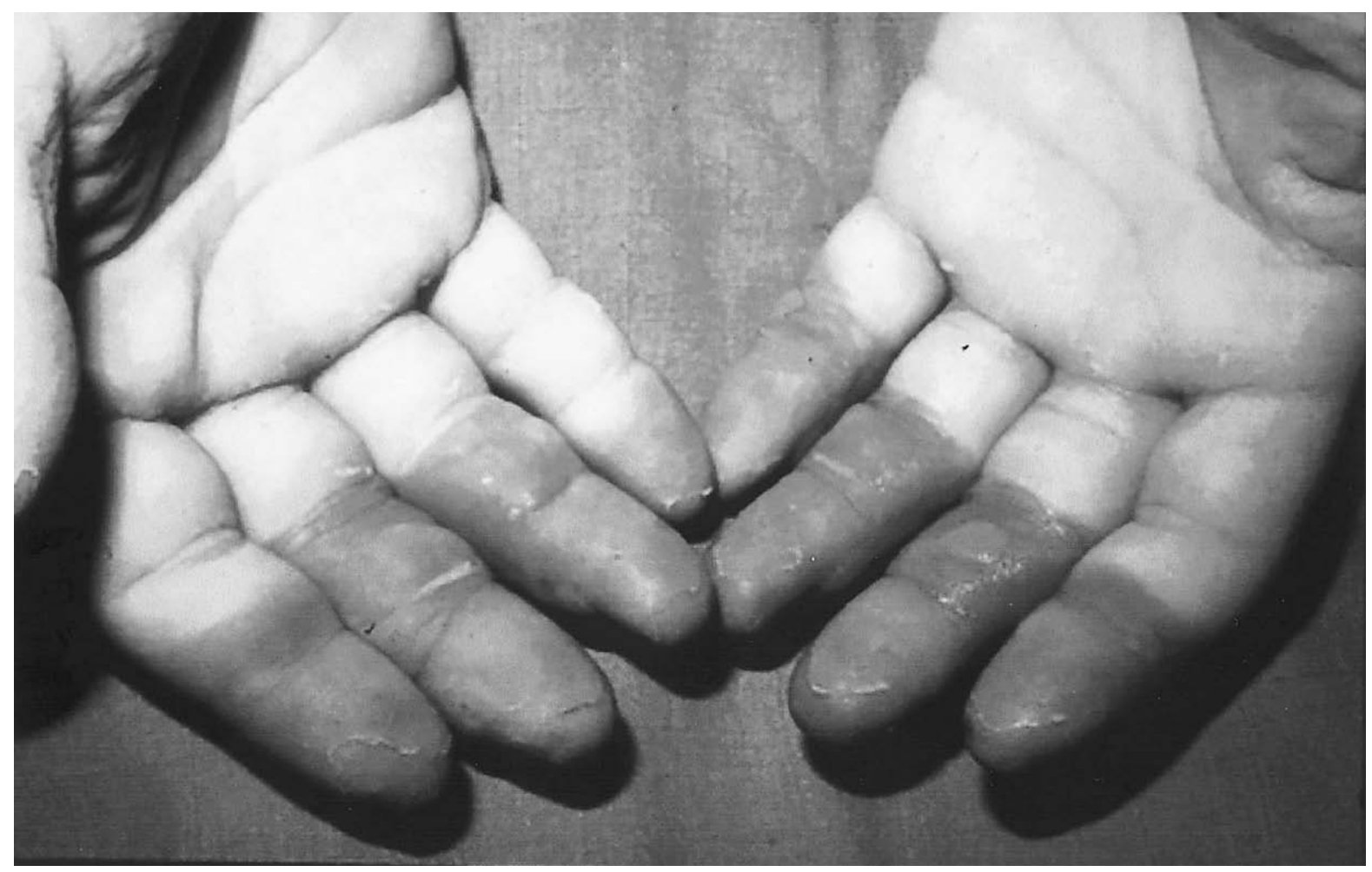

Figure 3. Frostbite injury of the hand at day 0: initial lesion extends beyond the distal phalanx (Grade 3).

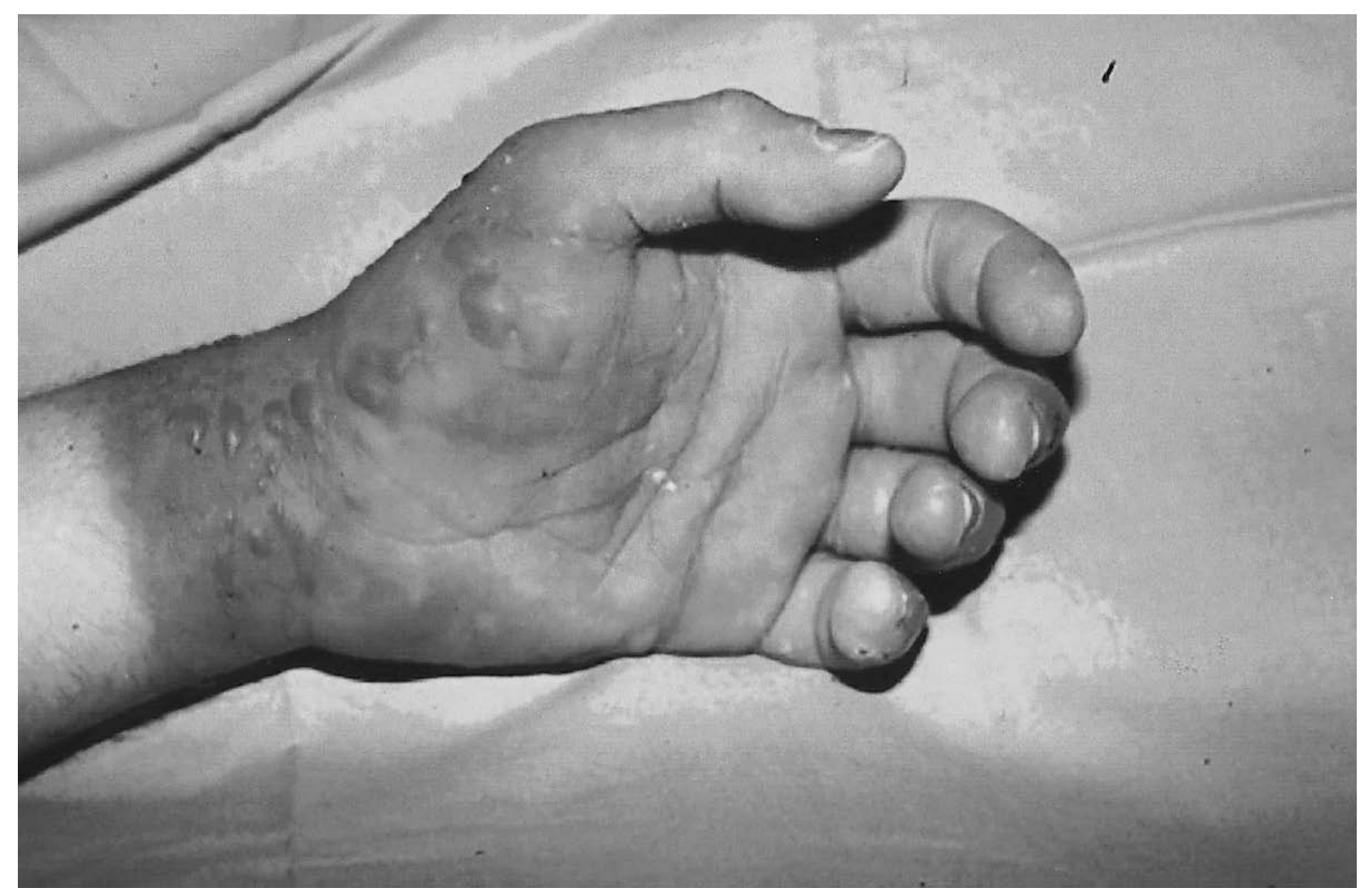

Figure 4. Frostbite injury of the hand at day 0, with initial lesion extending beyond the metacarpophalangeal joints (Grade 4). 
Table 3. Algorithm of management at day 0

\section{FROSTBITE INJURIES}

\section{OF}

THE EXTREMITIES

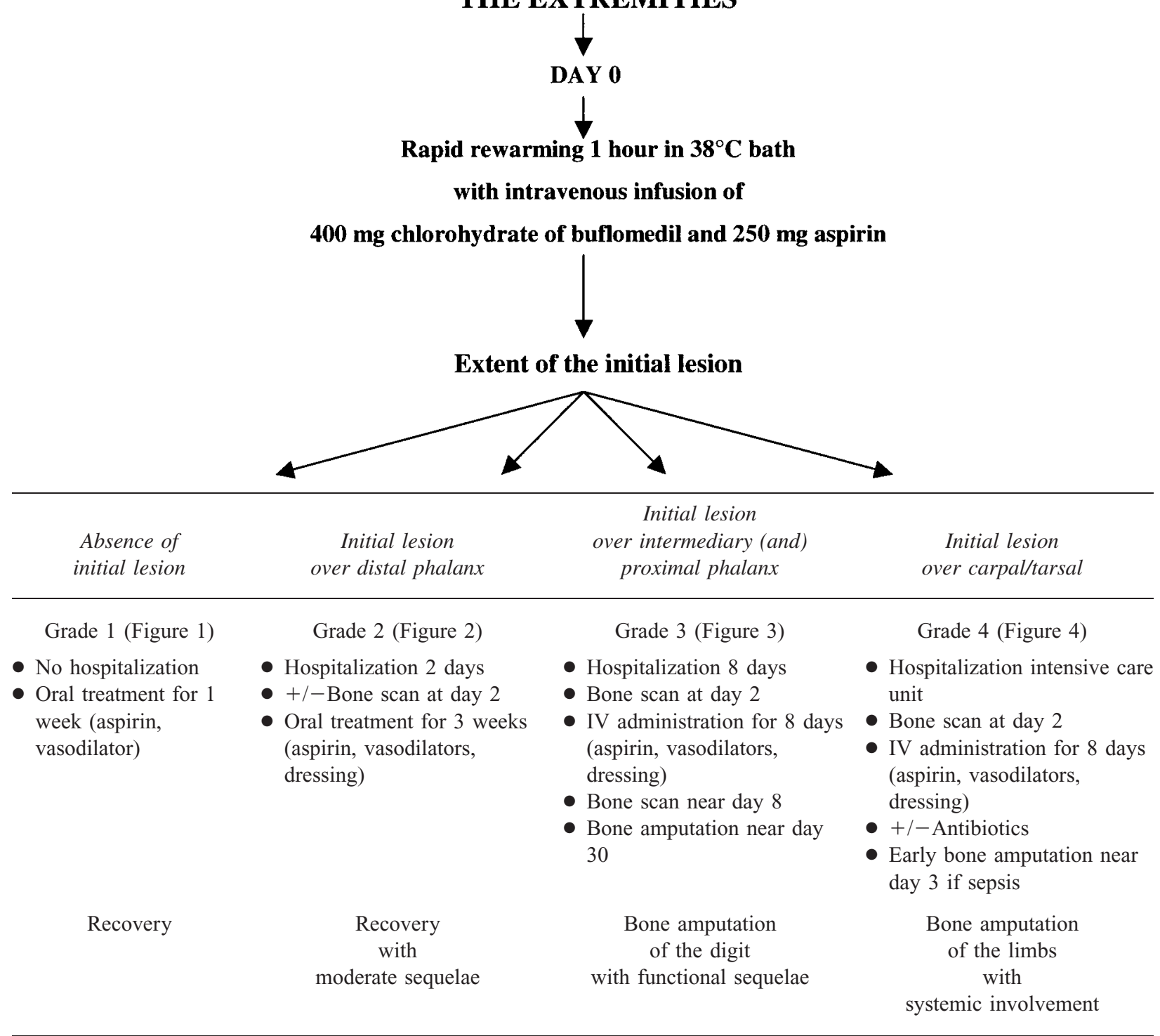

frostbite injuries. These may yield even more precise evaluations of frozen lesions.

\section{References}

1. Knize DM, Weatherley-White RC, Paton BC, Owens JC. Prognostics factors in the management of frostbite. J Trauma. 1969;9:749.

2. Heggers JP, Robson MC, Manavalen K, et al. Experimen- tal and clinical observations on frostbite. Ann Emerg Med. 1987;16:1056-1062.

3. Groechenig E. Treatment of frostbite with iloprost [letter]. Lancet. 1994;344:1152-1153.

4. Skolnick AA. Early data suggest clot-dissolving drug may help save frostbitten limbs amputation [news]. JAMA. 1992;267:2008-2010.

5. Zdeblick TA, Field GA, Shaffer JW. Treatment of experimental frostbite with urokinase. J Hand Surg Am. 1988; 13:948-953. 
6. Voinov AI. Clinical classification of cold injury and prognostication of the depth of tissue damage during the acute period. Klin Khir. 1989;12:41-43.

7. Chernetsov AA. The classification and treatment of frostbite. Voenno-Med Zh. 1992;10:26-28.

8. Botta-Kauer Y. Les brûlures de la main. Med Hyg. 1997; 55:2369-2372.

9. Mills WJ Jr. Clinical aspects of frostbite injury. IV. Frostbite. Proceeding of the Symposium on Arctic Medicine and Biology. 1964; Fort Wainwright, Alaska. Fort Wainwright, AL: Arctic Aeromedical Laboratory; 1964.

10. Mills WJ. Summery of treatment of the cold injured patient: frostbite. Alaska Med. 1993;35:61-66.

11. Killian H. Terminology and division into groups of localised cold injuries. In: Cold and Frost Injuries. Berlin: Springer-Verlag; 1981:25-37.

12. Foray J, Allamel G. Les gelures. In: Encycl Med Chir Paris. 1994;14-033-F-10.
13. Mazur P. Freezing of living cells: mechanisms and implications. Am J Physiol. 1984;247:125-142.

14. Vayssairat M, Priollet P, Magege A, Mousset E, Foray J. Does ketanserin relieve frostbite? Practitioner. 1986;230: 406-408.

15. Maurel A, Betrancourt JC, Van Frenkel R, et al. Action du buflomédil sur la microcirculation cutanée étudiée par un test de provocation au froid. J Mal Vasc. 1995;20:127-133.

16. Holmer I. Work in the cold. Review of methods for assessment of cold exposure. Int Arch Occup Environ Health. 1993;65:147-155.

17. Cauchy E, Chetaille E, Lefevre M, Kerelou E, Marsigny B. The role of bone scanning in severe frostbite of the extremities. A retrospective study of 88 cases. Eur J Nucl Med. 2000;48:497-502.

18. Greenwald D, Cooper B, Gottlieb L. An algorithm for early aggressive treatment of frostbite with limb salvage directed by triple-phase scanning. Plast Reconstr Surg. 1998;102:1069-1074. 